\section{Réplica del autor aludido}

\section{Author's reply}

Sr. Editor: En su carta en relación a mi artículo "Factores modificables de riesgo cardiovascular: ¿Cuáles estamos realmente modificando"?, Santos ${ }^{1}$ se refiere al impacto de una dieta apropiada en reducir el riesgo cardiovascular. Aporta un ejemplo clínico en el que resalta la importancia que tuvo en una paciente diabética con múltiples patologías asociadas implementar, entre otras medidas terapéuticas, una dieta rica en verduras, frutas y otros productos conteniendo abundantes omega $-3,-6$ y -9 PUFA para mejorar sus niveles de HDL, medidas en las que probablemente nadie podría estar en desacuerdo. Es precisamente en este sentido que en mi artículo comento que "el manejo clínico del riesgo modificable cardiovascular dependerá de las terapias que aporten el balance más favorable entre riesgo-beneficio y costo-efectividad para combatirlo" ${ }^{2}$. ¿Qué mejor ejemplo que el de una dieta apropiada como la que implementó Santos en su paciente?

Debo indicar que en mi revisión intenté resaltar, yendo más allá de la importancia clínica del manejo específico e individual del riesgo cardiovascular, la influencia de la posición socioeconómica en determinar conductas nocivas de salud que alimentan muchos de los factores conocidos de riesgo, y la necesidad de adoptar medidas eficientes al respecto.

Cito de mi artículo este párrafo: "La presente epidemia global de obesidad resalta aún más la importancia de estos cambios"2.

¿Qué programa podría ilustrar con claridad la importancia de medidas que a nivel de la sociedad pueden implementarse para reducir el riesgo cardiovascular? En Finlandia, en la década de 1970, en la región de Karelia del Norte, una iniciativa liderada por el Instituto Nacional de Salud Pública seguida por campañas educacionales a múltiples niveles en las que participaron la prensa y TV indujeron a la industria alimenticia, incluyendo hasta los establecimientos "McDonald's", a reducir significativamente el contenido de sal en los alimentos disponibles comercialmente. Treinta años más tarde se ha observado una reducción importante de la hipertensión $(10 \mathrm{~mm} / \mathrm{Hg}$ en la presión diastólica) asociada a una dramática reducción (cercana al 80\%) de los accidentes cerebrovasculares e infarto del miocardio en ese país ${ }^{3}$. En los Estados Unidos de Norteamérica el Institute of Medicine ha preconizado desde hace ya algún tiempo estas medidas de restricción del consumo de sal a nivel poblacional y recientemente la Federal Drug Administration, que regula y supervisa las industrias farmacéuticas y alimentarias, ha tomado cartas en el asunto, e impondrá (ya que tiene la autoridad para hacerlo) metas en el futuro próximo ${ }^{4}$. Otras metas similares ya han sido implementadas en establecimientos educacionales y de trabajo en diferentes países, limitando el consumo de bebidas azucaradas y ofreciendo colaciones dietéticamente bien balanceadas ${ }^{5}$. Un estudio en nuestro país por Albala y cols. ha ilustrado con claridad la importancia de estas medidas $^{6}$. Iniciativas a más largo plazo para mejorar el "built environment" ("ambiente construido"), que el desarrollo urbano mal planificado ha impuesto limitando el acceso de los sectores menos favorecidos de la población, que ven sus barrios saturados de ofertas de comida rápida o chatarra, a establecimientos que posibiliten mejores oportunidades de adquirir alimentos más saludables y a parques o áreas verdes que incentiven el ejercicio físico $^{7}$. Medidas de esta naturaleza pueden implementarse en cierta medida independientemente del nivel de desarrollo económico de la sociedad, aunque dependen del consenso y liderazgo que en ella se determinen. Un estudio prospectivo, multicéntrico y multiétnico, intentando analizar la interacción de todos los factores conocidos de riesgo cardiovascular, la posicion socioeconómica y el "ambiente construído", iniciado en 2002 seguramente aportará información importante sobre este tema ${ }^{8}$.

Es a este tipo de inciativas a las que me refiero en mi artículo cuando sostengo que, en contraste a lo que parece indicar Santos ${ }^{1}$ al final de su carta, "programas y políticas educacionales y de acceso a los recursos de salud tanto gubernamentales como del sector privado debieran ser parte importante de este proceso" 2 .

Tomás Romero, M.D.

University of California School of Medicine, San Diego, California.

Sharp Health Care, San Diego, California. Estados Unidos de Norteamérica. 


\section{Referencias}

1. Santos VM, Soares LA, Santos SC. Cardiovascular risk index and adequate nutrition (Letter to the editor). Rev Med Chile 2010; 138: 644-5

2. Romero T. Factores modificables de riesgo cardiovascular: ¿Cuáles estamos realmente modificando? Rev Med Chile 2009; 137: 1498-501.

3. Puska P. Successful prevention of non-communicable diseases: 25 year experiences with North Karelia Project in Finland. Public Health Medicine 2002; 4: 5-7.

4. Strategies to reduce sodium intake in the United States. National Academies Press. HTTP://www. NAP.EDU.

5. Hawkes C. The Worldwide Battle Against Soft Drinks in
Schools. Amer J Prev Med 2010; 38: 457-461.

6. Albala C, Ebbeling CB, Cifuentes M, Lera L, Bustos N, Ludwig DS. Effects of replacing the habitual consumption of sugar-sweetened beverages with milk in Chilean children. Am J Clin Nutr 2008; 88: 605-11.

7. Lovasi GS, Hutson MA, Guerra M, Neckerman KM. Built environments and obesity in disadvantaged populations. Epidemiol Rev 2009; 31: 7-20. [Epub 2009 Jul 9].

8. Teo K, Chow Ck, Vaz M, Rangarajan S, Yusuf S. Pure Investigators-Writing Group. The Prospective Urban Rural Epidemiology (PURE) study: examining the impact of societal influences on chronic noncommunicable diseases in low-, middle-, and high-income countries. Am Heart J 2009; 158: 1-7. 